\title{
Preeclampsia and genetic risk factors for thrombosis: A case- control study
}

\author{
Christianne J.M. De Groot, MD, a Kitty W.M. Bloemenkamp, MD, a Ella J. Duvekot, MD, ${ }^{\mathrm{d}}$ Frans M.

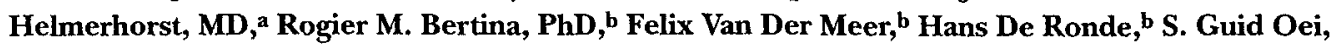 \\ MD, ${ }^{d}$ Humphrey H.H. Kanhai, MD, a and Frits R. Rosendaal, MD $^{\mathbf{c}}$ \\ Leiden and Veldhoven, The Netherlands
}

OBJECTIVE: Recently, it has been proposed that hereditary coagulation abnormalities leading to an increased venous thrombosis risk may play a role in the development of preeclampsia. We tested this hypothesis in women who have had preeclampsia compared with matched control subjects.

STUDY DESIGN: We conducted a case-control study of 163 women with preeclampsia during 1991-1996. Control subjects were matched for age and delivery date. Patients and control subjects were tested for the presence of factor $V$ Leiden, prothrombin $20210 \mathrm{~A}$ allele, protein $\mathrm{C}$, protein S, and antithrombin deficiency. Logistic regression methods were used for data analysis.

RESULTS: The prevalence of these genetic risk factors was similar in the patient group (12.9\%) and the control group (12.9\%; odds ratio, 1.0; 95\% confidence interval, 0.5-3.9). Unexpectedly, we found a high prevalence of factor $V$ Leiden in the control group (9.2\%).

CONCLUSION: We found no differences in the prevalence of genetic risk factors of thrombosis in women with preeclampsia compared with control subjects. (Am J Obstet Gynecol 1999;181:975-80.)

Key words: Preeclampsia, hereditary coagulation abnormalities, factor V Leiden, prothrombin 20210A allele, antithrombin deficiency

Preeclampsia, a pregnancy-specific syndrome clinically defined as elevated blood pressure and proteinuria, remains an important cause of maternal and fetal morbidity and mortality despite intensive research.1, 2 Its pathogenesis is unknown, but genetic, immunologic factors and abnormal placentation have been proposed to play a causative role. Abnormal placentation early in pregnancy might result in restricted blood flow to the placental-fetal unit and subsequent liberation of cytotoxic factors. These factors may result in endothelial damage clinically manifested by a systemic maternal syndrome. ${ }^{3,4}$

Recently, abnormal placentation has been associated with an increased tendency toward thrombosis. 5,6 The tendency toward thrombosis in women with preeclampsia might be the result of the combination of an acquired risk factor (pregnancy) with a genetic risk factor for venous thrombosis. Recently, the discovery of common ge-

From the Departments of Obstetncs, Gynecology, and Reproductive Sciences, ${ }^{a}$ Hemostasis and Thrombosis, ${ }^{b}$ and Clinical Epidemiology, Leiden University Medical Center, and the Department of Obstetrics and Gynecology, St Joseph Hospulal Veldhoven.d

Received for publication February 2, 1999; revised April 21, 1999; accepted May 11, 1999.

Reprint requests: Christianne J.M. De Groot, Department of Obstetrics and Gynecology, Westeinde Hospilal, Lijnbaan 32, PO Box 432, 2501

CK The Hague, The Vetherlands.

Copyright 101999 by Mosby, huc.

$0002-9378 / 99 \$ 8.00+06 / 1 / 99968$ netic risk factors for venous thrombosis, such as factor $\mathrm{V}$ Leiden ${ }^{7}$ and prothrombin 20210 A allele, ${ }^{8}$ resulted in the hypothesis that genetic risk factors of thrombosis might play a causative role in the development of preeclampsia. Therefore the aim of this study was to compare the prevalence of inherited risk factors for thrombosis, including factor $\mathrm{V}$ Leiden, prothrombin $20210 \mathrm{~A}$ allele, protein $\mathrm{C}$, protein $\mathrm{S}$, and antithrombin deficiency, in women who have had preeclampsia in their first pregnancy and in matched control subjects with an uneventful pregnancy.

\section{Material and methods}

Study design. Women who had preeclampsia during their first pregnancy were selected from a computer database and patient charts. Included were women who were delivered of their neonates on the obstetric service of the Leiden University Medical Center $(\mathrm{n}=117)$ or at the St Joseph Hospital Veldhoven $(\mathbf{n}=81)$ in the period from January 1, 1991, through December 31, 1996. The study was approved by the Committee on Ethics in Human Research of both hospitals.

Preeclampsia and eclampsia were defined after the completion of pregnancy by means of strict criteria ${ }^{9}$ : rise of blood pressure ( $\geq 30 \mathrm{~mm} \mathrm{Hg}$ systolic or $\geq 15 \mathrm{~mm} \mathrm{Hg}$ diastolic over values in the first 20 weeks or, if blood pressure was unknown, before 20 weeks of gestation); late- 
Table I. Description of medical reasons for in-hospital delivery of control group and prevalence of factor $V$ and prothrombin 20210A allele

\begin{tabular}{|c|c|c|c|}
\hline & $\begin{array}{c}\text { Total } \\
\text { No. }\end{array}$ & $\begin{array}{c}\text { Factor } V \\
\text { Leiden } \\
(\text { No. })\end{array}$ & $\begin{array}{c}\text { Prothrombin } \\
20210 \mathrm{~A} \text { allele } \\
\text { (No.) }\end{array}$ \\
\hline Preterm labor & 8 & 3 & 0 \\
\hline $\begin{array}{l}\text { Abnormal second stage } \\
\text { of labor }\end{array}$ & 27 & 2 & 1 \\
\hline Meconium staining & 15 & 2 & 0 \\
\hline Postterm pregnancy & 11 & 1 & 0 \\
\hline Breech delivery & 20 & 1 & 0 \\
\hline $\begin{array}{l}\text { Prolonged ruptured } \\
\text { membranes }\end{array}$ & 13 & 1 & 0 \\
\hline Uterine leiomyomas & 3 & 1 & 0 \\
\hline Symphysis pain & 1 & 1 & 0 \\
\hline $\begin{array}{l}\text { Abnormal first stage of } \\
\text { labor }\end{array}$ & 17 & 1 & I \\
\hline Physiologic factor & 12 & 2 & 1 \\
\hline Infertility & 6 & 0 & 1 \\
\hline Urinary tract infection & 1 & 0 & 1 \\
\hline $\begin{array}{l}\text { Abnormal third stage of } \\
\text { labor }\end{array}$ & 6 & 0 & 1 \\
\hline $\begin{array}{l}\text { Intrauterine growth } \\
\text { restriction }\end{array}$ & 3 & 0 & 0 \\
\hline Other reason & 20 & 0 & 0 \\
\hline TOTAL & 163 & 15 & 6 \\
\hline
\end{tabular}

pregnancy hypertension (defined as an absolute blood pressure $\geq 140 / 90 \mathrm{~mm} \mathrm{Hg})$; and proteinuria $(\geq 2+[100$ $\mathrm{mg} / \mathrm{dL}]$ on a voided specimen or $\geq 1+[30 \mathrm{mg} / \mathrm{dL}]$ on a catheterized specimen). All women defined as having preeclampsia fulfilled the criteria of a rise of blood pressure as described. Of these women, 4 with preeclampsia had an absolute blood pressure in late gestation of $<140 / 90 \mathrm{~mm} \mathrm{Hg}$ (average \pm SEM, 131/85 $\pm 4 / 0 \mathrm{~mm} \mathrm{Hg}$ ).

Severe preeclampsia is defined as an absolute diastolic blood pressure of $\geq 110 \mathrm{~mm} \mathrm{Hg}$ and proteinuria $(\geq 2+$ $[100 \mathrm{mg} / \mathrm{dL}])$ on a catheterized specimen at admission. Excluded from the study and control groups were women who had multiple pregnancies, chronic hypertension, renal disease, diabetes, collagen vascular diseases, cancer, or thrombosis before their first pregnancy. None of the women with preeclampsia had venous thrombosis before or during the first pregnancy, and thus none were excluded on the basis of this criterion. We found 198 consecutive patients that were eligible for the study. Of these women, $163(82 \%)$ were willing to participate in the study; $35(18 \%)$ women with preeclampsia did not enter the study for the following personal reasons ( 18 from the Leiden University Medical Center and 17 from the St Joseph Hospital Veldhoven): were unwilling to spend time $(n=10)$, had an unknown address $(n=6)$, were unwilling to undergo venipuncture $(\mathrm{n}=3)$, expected insurance problems after deoxyribontcleic acid analısis $(n=7)$, had a current pregnancy $(n=$
3), had language problems $(n=2)$, or did not want to be reminded of the period of preeclampsia $(n=4)$.

Control subjects were selected from the same computer database according to the following criteria: first pregnancy, no rise in blood pressure, no hypertension or proteinuria, similar age ( \pm 5 years), no biologic relationship, and a delivery date as close as possible to the delivery date of a patient. The exclusion criteria applied were the same as those for the patients. A total of 229 control subjects were asked to enter the study, and $66(29 \%)$ refused for the following reasons ( 46 from the Leiden University Medical Center and 20 from the St Joseph Hospital Veldhoven): were unwilling to spend time $(n=$ $19)$, had an unknown address $(n=23)$, were unwilling to undergo venipuncture $(n=7)$, expected insurance problems after deoxyribonucleic acid analysis $(n=7)$, had a current pregnancy $(n=7)$, or had a language problem ( $n$ $=3$ ). A detailed description of the reasons for delivery in the hospital of the control group is provided in Table I. Clinical and demographic data are summarized in Table II. Intrauterine growth restriction was defined according to the birth weights as $<5$ th percentile, as described by Kloosterman. ${ }^{10}$

After informed consent was obtained, blood samples were drawn, and a standard questionnaire was completed containing questions about personal and family history of venous thrombosis. This was done because the willingness to participate in the study (especially in the control group) might be influenced by the perception of an increased risk known through a family history of venous thrombosis. We called a family history positzve when venous thrombosis was reported in one or more first- or second-degree relatives of the patient or control subject. The questionnaire also included questions about a family history of hypertension, height and weight, and smoking habits.

Laboratory studies. Blood was collected from the antecubital vein into Monovette tubes (Sarstedt, Nümbrecht, Germany) containing $0.106 \mathrm{~mol} / \mathrm{L}$ trisodium citrate. 7,11 Plasma was prepared by centrifugation for 10 minutes at $2000 \mathrm{~g}$ at room temperature and stored at $-70^{\circ} \mathrm{C}$ in 1.5 $\mathrm{mL}$ volumes until used. High-molecular-weight deoxyribonucleic acid was isolated from leukocytes and stored at $4^{\circ} \mathrm{C}$. Factor V Leiden, ${ }^{12}$ prothrombin $20210 \mathrm{~A}$ allele, ${ }^{13}$ protein $\mathrm{C}$ antigen, ${ }^{14}$ and total protein $\mathrm{S}$ antigen ${ }^{15}$ levels were determined as described elsewhere. Antithrombin activity was measured with the antithrombin kit (Chromogenix AB, Mölndal, Sweden) on an ACL 300. The technician was blinded to the status of the sample (ie, whether it was from a woman who had preeclampsia or a control subject). The results are expressed as present or absent for factor $\mathrm{V}$ Leiden and prothrombin $20210 \mathrm{~A}$ allele or in units per milliliter, where $1 \mathrm{U}$ refers to the activity or antigen present in $1 \mathrm{~mL}$. of pooled nor- 
Table II. Clinical and demographic data of women who had preeclampsia and matched control subjects

\begin{tabular}{lcc}
\hline & $\begin{array}{c}\text { Women with } \\
\text { preclampsia }(n=163)\end{array}$ & $\begin{array}{c}\text { Conitrol subjects } \\
(n=163)\end{array}$ \\
\hline Maternal age at delivery $(y)$ & $28 \pm 0.3$ & $28 \pm 0.3$ \\
Gestational age at delivery $(\mathrm{d})$ & $242 \pm 3$ & $276 \pm 2 *$ \\
Systolic blood pressure at $<20$ weeks' gestation $(\mathrm{mm} \mathrm{Hg})$ & $127 \pm 7$ & $118 \pm 1$ \\
Diastolic blood pressure at $<20$ weeks' gestation $(\mathrm{mm} \mathrm{Hg})$ & $71 \pm 0.5$ & $69 \pm 0.5$ \\
Systolic blood pressure at $>20$ weeks' gestation $(\mathrm{mm} \mathrm{Hg})$ & $151 \pm 1$ & $123 \pm 1^{*}$ \\
Diastolic blood pressure at $>20$ weeks' gestation $(\mathrm{mm} \mathrm{Hg})$ & $101 \pm 1$ & $77 \pm 1^{*}$ \\
Proteinuria $(\mathrm{mg} / \mathrm{dL})$ & $30-100$ & $<30^{*}$ \\
Race $(\%$ white) & 96 & 96 \\
\hline
\end{tabular}

Data are mean \pm SEM.

$* P<.05$, versus control subjects.

Table III. Number and frequency of subjects with factor V Leiden and prothrombin 20210A allele

\begin{tabular}{|c|c|c|c|c|c|}
\hline & \multicolumn{2}{|c|}{$\begin{array}{l}\text { Women with preeclampsia in } \\
\text { first pregnancy }(n=163)\end{array}$} & \multicolumn{2}{|c|}{$\begin{array}{l}\text { Control subjects } \\
\quad(n=163)\end{array}$} & \multirow{2}{*}{$\begin{array}{c}\text { Odds ratio and } \\
95 \% \text { confidence interval }\end{array}$} \\
\hline & No. & $\%$ & No. & $\%$ & \\
\hline Factor V Leiden & 16 & 9.8 & 15 & 9.2 & $1.07(0.51-2.25)$ \\
\hline Prothrombin $20210 \mathrm{~A}$ allele & 5 & 3.1 & 6 & 3.7 & $0.83(0.25-2.77)$ \\
\hline
\end{tabular}

mal plasma $(1 \mathrm{U} / \mathrm{mL}=100 \%)$, for protein $\mathrm{C}$, protein $\mathrm{S}$, and antithrombin. The criteria for the diagnosis of protein deficiencies were plasma levels $<0.63 \mathrm{U} / \mathrm{mL}$ for protein $\mathrm{C}$ and total protein $S$ and $<0.80 \mathrm{U} / \mathrm{mL}$ for antithrombin (combined with normal values for prothrombin and prothrombin time to exclude vitamin $\mathrm{K}$ deficiency). All subjects with positive test results for factor V Leiden or prothrombin 20210A allele or suspected of a protein $\mathrm{C}$, protein $\mathrm{S}$, or antithrombin deficiency were seen on a second occasion for further evaluation. All subjects thought to have a protein $\mathrm{C}$, protein $\mathrm{S}$, or antithrombin deficiency after the first analysis were, on the second occasion, at least 12 weeks post partum and/or had stopped coumarin therapy for at least 12 weeks.

Statistical analysis. We calculated relative risks as estimates of the odds ratios by simple cross-tabulation for factor $V$ Leiden or prothrombin 20210A allele. We analyzed women who had preeclampsia and several risk factors, including a family history of thrombosis and hypertension, body mass, smoking, and coagulation mutations, versus control subjects by means of unconditional logistic regression techniques that allow adjustments for these factors simultaneously. Demographic and clinical data are presented as patient group means with an SE or SD.

\section{Results}

A total of 163 women with preeclampsia entered the study; 99 were delivered of their neonates in the Leiden University Medical Center and 64 in the St Joseph Hospital Veldhoven. The frequency of the factor $\mathrm{V}$ Leiden and prothrombin $20210 \mathrm{~A}$ allele was not different between women who had preeclampsia and their control subjects (Table III). No differences were found in the frequency of factor V Leiden between the Leiden University Medical Center and the St Joseph Hospital Veldhoven for women who had preeclampsia (9 [9.1\%] and 7 [10.9\%], respectively) and for the control subjects (8 $[8.1 \%]$ and 7 [10.9\%], respectively). Similar results were found for the prothrombin 20210A allele in subjects from the Leiden University Medical Center versus St Joseph Hospital Veldhoven for women who had preeclampsia (3 [3.0\%] and $2[3.1 \%]$, respectively) and control subjects (4 [4.0\%] and 2 [3.1\%], respectively). In all women who had positive test results for either factor $V$ Leiden or prothrombin 20210A allele, results were confirmed in a second blood sample; all were heterozygous for the mutation. After a second analysis, which included the further evaluation of subjects with initially low levels of protein $C$ $(n=2)$, total protein $S(n=5)$, or antithrombin $(n=3)$, persistently low levels were detected in only 1 woman diagnosed with an antithrombin deficiency, who had preeclampsia in her first pregnancy. The discrepancy between results of the first and second analyses can be explained by pregnancy, postpartum period, coumarin use, or hormone treatment at the time of first blood collection. Overall, the prevalence of genetic risk factors for thrombosis (any coagulation disorder) was similar in both groups $(12.9 \%$ in the patients and $12.9 \%$ in the control subjects; odds ratio, $1.00 ; 95 \%$ confidence interval, 0.52-3.88).

The unexpectedly high frequency of factor $V$ Leiden in our control group was further analyzed for factors that 
Table IV. Adjusted odds ratıos for several variables for preeclampsia

\begin{tabular}{lcc}
\hline \multicolumn{1}{c}{$\begin{array}{c}\text { Ratio of women } \\
\text { With preeclampsia } \\
\text { Variable }\end{array}$} & $\begin{array}{c}\text { Odds ratio and } \\
\text { subjects (No) }\end{array}$ & $\begin{array}{c}\text { 95\% confidence } \\
\text { interval }\end{array}$ \\
\hline Thrombosis in family & $36 / 37$ & $096(040-288)$ \\
Hypertension in family & $93 / 70$ & $166(106-1008)$ \\
Body mass index & $76 / 57$ & $151(095-811)$ \\
Smoking & $18 / 29$ & $054(028-242)$ \\
Factor VLeiden & $16 / 15$ & $119(055-438)$ \\
\hline
\end{tabular}

Simultaneous adjustment for different variables was made in a logistic model

might have influenced this increased prevalence A positive family history of venous thrombosis (Table IV) was found as frequently among women who had preeclampsia during their first pregnancy $(n=36)$ as among the matched control subjects $(n=37)$, indicating no differences in baseline risk After adjustment for positive famlly history for thrombosis, hypertension, body mass index, smoking, and the factor $V$ Leiden mutation, the odds ratios for preeclampsia and factor $V$ Leiden remained essentrally the same We found an almost 2-fold higher risk for preeclampsia in women with a positive family history of hypertension

Further analysis showed that important clinical outcome vanables were associated with genetic risk factors of thrombosis First, control subjects with factor V Leiden $(n=15)$ were delivered at a lower gestational age than control subjects without factor V Leiden ( $n=148,269 \pm$ 20 [SD] days vs $279 \pm 17$ days, respectively), and thus their babies had lower burth weights $(2997 \pm 581 \mathrm{~g}$ vs 3303 $\pm 560 \mathrm{~g})$ No differences in gestational age or birth weight were found among women with preeclampsia with positive or negative test results for factor $V$ mutation $(\mathrm{n}=16,238 \pm 26$ days vs $240 \pm 35$ days, $1912 \pm 867 \mathrm{~g}$ vs $1941 \pm 951 \mathrm{~g}$, respectively)

Second, the frequency of factor $V$ Leiden was also not greater in women who had severe preeclampsia $(2 / 37)$ than in control subjects $(15 / 163$, odds ratio, $051,95 \%$ confidential interval, 0 12-2 67) Similar results were found by using gestational age (delivery before 238 days) to indicate severe preeclampsia ( $7 / 76$, hypertension and proteinuria defined as for preeclampsia, odds ratıo, 10 , 95\% confidential interval, $04-35$ )

Third, none of the women in whom thrombosis developed $(n=5)$ after their first pregnancy, including 4 women who had preeclampsia and 1 control subject, had positive test zesults for factor $V$ Leiden, prothrombin $20210 \mathrm{~A}$ allele, or antithrombin deficiency (follow-up median, 26 months, range, 0 5-76 months)

Fourth, none of the women who had eclampsid ( $\mathrm{n}=$ 11), of whom 8 were in the antepartum period and 3 were in the postpartum penod, had positive results for one of the coagulation mutations

Fifth, intrauterine growth restriction was found in 18 women who had preeclampsia, of whom 1 had posituve results for both factor $\mathrm{V}$ Leiden and prothrombin 20210A allele, and 9 control subjects, of whom none were positive for a coagulation mutation There were no statistical differences for coagulation deficiencies among patients and control subjects

Sixth, intrauterine fetal death was found in 18 women who had preeclampsia, of whom 2 women had positive test results for prothrombin $20210 \mathrm{~A}$ allele

\section{Comment}

We found no differences in the prevalence of inherited risk factors for venous thrombosis, including factor V Leiden, prothrombin $20210 \mathrm{~A}$ allele, and protein $\mathrm{C}$, protem $S$, and antithrombin deficiencies, in women who had preeclampsia in their first pregnancy and in control subjects with an uneventful pregnancy This is in contrast with data from previous published studies 616,17 One explanation is the unexpectedly high frequency of factor $\mathrm{V}$ Leiden in the control group (92\%) in this study We therefore compared the frequency of the factor V Leiden mutation among women who had preeclampsia with that of a different control group examined previously 18 This group consisted of a subset of the onginal control group of the Leiden Thrombophila Study In that study 474 consecutive patients with thrombosis were matched with 474 control subjects who exther were acquaintances asked to partucipate by the patients or were partners of the patients From these control groups we selected, for the current analysis, women who had experienced at least 1 pregnancy, had no history of venous thrombosis, were premenopausal, were not pregnant, were not in the puerperium, and had no recent miscarriage (total women included, 105) ${ }^{18}$ We found a higher frequency for factor $V$ Leiden in women who had preeclampsia versus these control subjects (odds ratio, $370,95 \%$ confidence interval, 1051303 ) When we compare the frequency of the prothrombin 20210A allele among women who had preeclampsia with that of the same alternative control group ${ }^{18}$ (total women included, 105, prothrombin 20210A allele positive, 3), no differences in frequency were found for prothrombin 20210A allele (odds ratio, $108,95 \%$ confidence interval, 025460 ) DizonTownson et al ${ }^{16}$ reported a frequency of factor $V$ Leiden in an American obstetric population of $42 \%(n=403)$, which is similar to the frequency described in the Leiden Thrombophilia Study and a large Amencan study (3\% $4 \%)^{19}$ and almost 3 umes lower than the trequency observed in the control subjects recruited in our studv Dison-Townson et al ${ }^{16}$ also reported a frequency of factor 1 I eiden of $3 \%$ in an unselected group of gravid women Howerel higher frequencies of factor V Leiden have also 
been described by Pauer et al ${ }^{21}$; frequencies of $9.2 \%$ (8/87 of an unselected group of healthy women with no history of fetal losses) and as high as $12 \%$ have been reported in some selected groups with a history of venous thrombosis or pulmonary embolism. ${ }^{22}$

If the high frequency of factor $V$ Leiden was too high in our control group, we can speculate about selection bias. We estimated that if all women who refused to enter the study had negative test results for factor $V$ Leiden we still would have found a frequency of $6.6 \%$ (15/229). Again, no differences would then be apparent between patients and control subjects. Moreover, given the reason for not entering these control subjects into the study, this seems unlikely to explain the high prevalence of factor $\mathrm{V}$ Leiden in the control subjects of our study. No statistical differences were found for the reasons for refusal to enter the study among patients and control subjects. A second possibility is that women who undergo delivery in a hospital are different from all women giving birth; in The Netherlands about one third of the deliveries are at home. Although control subjects with positive test results for factor $\mathrm{V}$ Leiden had a relatively high frequency of preterm labor $(3 / 15)$, no differences were found among patients and control subjects when the subjects with preterm labor were excluded (odds ratio, 1.34; 95\% confidence interval, 0.61-4.97). As described in Table IV, we also found no difference between the 2 groups for family history of thrombosis nor was there a difference in family history for thrombosis among control subjects of our study and the alternative control group described previously in this section, with a lower frequency of the factor $V$ Leiden mutation ( $\mathrm{n}=37$ and 23 , respectively; odds ratio, $1.0 ; 95 \%$ confidence interval, 0.24-3.33). ${ }^{18}$ Nevertheless, we cannot rule out the possibility that women who undergo delivery in the hospital are not fully representative of the prevalence of heritable coagulation mutations of all gravid women.

Another explanation why others found a difference in the frequency of coagulation abnormalities in both women with preeclampsia and the control subjects is that they found a particularly high incidence of coagulation abnormalities among the patients. Dekker et al ${ }^{17}$ reported a $16 \%$ rate of activated protein $\mathrm{C}$ resistance in severe-onset preeclampsia. Bertina et $\mathrm{al}^{7}$ have shown that $80 \%$ to $100 \%$ of persons with laboratory-confirmed activated protein $C$ resistance are either heterozygous or homozygous for the factor $V$ Leiden mutation. As suggested by Dizon-Townson et al, ${ }^{16}$ the high rate of activated protein $\mathrm{C}$ resistance might be the result of a different definition of pregnancy-induced hypertension; $39 \%$ had chronic hypertension versus $3.1 \%$ in this study of women with preeclampsia, and $89 \%$ were nulliparous. ${ }^{17}$ Differences in definition, methods, and cutoff levels used might explain the high frequency of activated protein C resistance. However, Dizon-Townson et al ${ }^{16}$ described a frequency of factor $V$ Leiden that was similar to that found in our study ( $\mathrm{n}=158,8.9 \%)$ in women with severe preeclampsia. Recently, Kupferminc et al ${ }^{6}$ reported a prevalence of $53 \%$ of inherited thrombophilia in women with severe preeclampsia, including $26 \%(9 / 34)$ with factor $V$ Leiden. Furthermore, it is unlikely that our results are explained by the geography of our population because the frequency of factor $V$ Leiden was similar in the population of 2 different hospitals from 2 different regions of the country. Both groups had an identical ethnic origin (96\% white), which was very similar to that described by Dizon-Townson et al ${ }^{16}$ ( $94 \%$ white).

Several important outcome variables of preeclampsia were evaluated and associated with coagulation mutations, including thrombosis, eclampsia, intrauterine growth restriction, and intrauterine fetal death. We did not find an association between these variables and an increased frequency of genetic risk factors (factor $\mathrm{V}$ Leiden, prothrombin 20210A allele, and antithrombin deficiency). However, the number of specific outcome variables is small, and because of the study design, the findings are post hoc.

The frequency of thrombosis is relatively high ( $1.5 \%)$ in the 2 study groups (identical in patients and control subjects) compared with what has been reported previously. ${ }^{23}$ This might be explained by the group of women studied; $52 \%$ of the women who had preeclampsia were delivered by cesarean compared with $6 \%$ in the control group (odds ratio, 16.2; $95 \%$ confidence interval, 8.0-9.3 $\times 10^{6}$ ). Furthermore, in this study the frequency of thrombosis is described by using a questionnaire. All women who had thrombosis after their first pregnancy explained that the diagnosis was confirmed with ultrasonography or ventilation-perfusion scanning. A referral bias in the perception of increased risk that might lead doctors to intensify their diagnostic and referral behavior for women who have been sick during pregnancy cannot be excluded. In this study thrombosis did not develop in any of the women with genetic risk factors for thrombosis during the first pregnancy. The estimate of thrombotic risk for women with a factor $V$ Leiden mutation varies from $0.3 \%$ to $2 \%$ of pregnancies. ${ }^{23}$, 24 Therefore these data do not support the use of thromboprophylaxis in first pregnancies of women with a factor $V$ Leiden or prothrombin 20210A allele because the necessary use of anticoagulants will increase fetal and maternal morbidity and mortality rates, whereas only a few thrombotic events would be prevented. The benefit-to-risk ratio of using thromboprophylaxis in pregnancies of women with a genetic coagulation disorder and other genetic or acquired risk factors, including severe preeclampsia, needs to be evaluated in large, prospective, randomized, controlled studies. 25

In conclusion, in our case-control study we found no increased frequency of the genetic risk factors for throm- 
bosis in women who had preeclampsia in their first pregnancy compared with control subjects with an uneventful pregnancy in the hospital Unexpectedly, we found a high frequency of factor V Leiden in the control group

\section{REFERENCES}

1 Geary $M$ The HELPP syndrome $\mathrm{Br} J$ Obstet Gynaecol 1997,104 887-91

2 Roberts JM, Redman CW Pre-eclampsia more than pregnancy induced hypertension Lancet 1993,341 1447-51

3 Roberts JM, Taylor RN, Muscı TJ, Rodgers GM, Hubel CA McLaughlın MK. Preeclampsia an endothelial cell disorder Am J Obstet Gynecol 1989,161 1200-4

4 de Groot CJM, Taylor RN Preeclampsta an update Eur J Obstet Gynecol Reprod Biol 1996,69 59-60

5 Dizon Townson DS, Meline L, Nelson LM, Varner M, Ward K Fetal carners of the factor $V$ Leiden mutation are prone to miscarriage and placental infarction Am J Obstet Gynecol $1997,177402-5$

6 Kupferminc MJ, Eldor A, Steinman N, Many A, Bar-Am A, Jaffa $A$, et al Increased frequency of genetuc thrombophilia in women with complications of pregnancy $\mathrm{N}$ Engl J Med 1999,340 9-13

7 Bertina R, Koeleman B, Koster T, Rosendaal F, Dirven R, de Ronde $\mathrm{H}$, et al Mutation in blood coagulation factor $\mathrm{V}$ associ ated with resistance to activated protein C Nature 1994,369 64-

8 Poort SR, Rosendaal FR, Reıtsma PH, Bertuna RM A common genetic vanation in the 3 untranslated region of the prothrom bin gene is assocrated with elevated plasma prothrombin levels and an increase in venous thrombosis Blood 1996,88 3698-703

9 National high blood pressure education program workıng group report on high blood pressure in pregnancy Am J Obstet Gynecol 1990,163 1689-712

10 Kloosterman GJ On intrauterine growth, the significance of prenatal care Int J Gynaecol Obstet 1970,8 895912

11 Dahlbäck B Factor V gene mutation causıng inherited resis tance to activated protem $\mathrm{C}$ as a basis for venous thromboembolism J Int Med 1995,237 221-7

12 de Ronde $\mathrm{H}$, Bertina $\mathrm{R}$ Laboratory diagnosis of APC-resistance a critical evaluation of the test and the development of diagnostic cntena Thromb Haemost 1994,72 880-6
13 Poort S, Bertina $\mathrm{R}$ Vos $\mathrm{H}$ Rapid detection of the Prothrombin 20210 A variation by allele specific PCR Thromb Haemost 1997,7811578

14 Boyer C, Rothchild C, Wolf M, Amiral J, Meyer D, Lameu M A new method for the estimation of protein $C$ by ELISA Thromb Res 1984,36 579-89

15 Deutz Terlouw $P$, Ballernng $L$, van Wyngaarden A, Bertuna $R$ Two ELISA's for measurement of protein $S$ and their use in the laboratory diagnosis of protein $S$ deficiency Clin Chim Acta $1989,186321-34$

16 Dizon-Townson DS, Nelson LM, Easton K, Ward K. The factor V Leiden mutation may predispose women to severe preeclampsia Am J Obstet Gynecol 1996,175 902-5

17 Dekker GA, de Vries JI, Doelıtzsch PM, Huygens PC, von Blomberg BM, Jacobs C, et al Underlyng disorders with severe early-onset preeclampsia Am J Obstet Gynecol 1995,173 1042-8

18 Bloemenkamp KWM, Rosendaal FR, Helmerhorst FM Enhancement by factor V Leiden mutation of risk of deep-ven thrombosis associated with oral contraceptrves containing third generation progestogen Lancet 1995,346 566-8

19 Ridker PM, Miletich JP, Hennekens CH, Buring JE Ethnic dis tribution of Factor $\mathrm{V}$ Leiden in 4047 men and women Implications for venous thromboembolism screening JAMA $1997,2771305^{-7}$

20 Dizon-Townson DS, Nelson LM, Jang $H$, Varner MW, Ward $K$ The incidence of the factor $V$ Leiden mutation in an obstetric population and its relationship to deep vein thrombosis Am J Obstet Gynecol 1997,176 883-6

21 Pauer $\mathrm{H} \mathrm{U,} \mathrm{Neesen} \mathrm{J,} \mathrm{Hinney} \mathrm{B} \mathrm{Factor} \mathrm{V} \mathrm{Leiden} \mathrm{and} \mathrm{its} \mathrm{rele-}$ vance in patients with recurrent abortions [letter] Am J Obste Gynecol 1998,178 629

22 Price DT, Rudker PM Factor V Leiden mutation and the risks for thromboembolic disease a clinical perspective Ann Intern Med 1997,127 895-903

23 McColl MD, Ramsay JE, Tatt RC, Walker ID, McCall F, Conkse JA, et al Risk factors for pregnancy associated venous throm boembolısm Thromb Haemost 1997,78 1183-8

24 Middeldorp S, Henkens CMA, Koopman MMW, van Pampus ECM, Hamulyak $\mathrm{K}$, van der Meer J, et al The incidence of venous thromboembolısm in family members of patients with fac tor V Leiden mutation and venous thrombosis Ann Intern Med $1998,1 \quad 15-20$

25 Sibaı BM Thrombophilias and adverse outcomes of preg nancy-what should a clinican do? $\mathrm{N}$ Engl J Med 1999,340 50-2 